\title{
PESQUISA, PODER E SAÚDE
}

\author{
Maria Cecilia Puntel de Almeida*
}

\section{Introduçáo}

Congratulo-me com a Escola de Enfermagem da Universidade de São Paulo que comemora seus 50 anos de existência e que, para abrilhantar este jubileu, organiza e promove este Encontro Internacional sobre Pesquisa em Enfermagem, questáo esta tão importante para a área e que contribui, em certa medida, para as transformações da prática de enfermagem.

O tema desta mesa é Pesquisa, Poder e Saúde e como tal não posso falar de enfermagem e pesquisa no Brasil sem apontar a Escola de Enfermagem da Universidade de São Paulo como uma das instituiçóes de ensino superior de formação de recursos humanos em enfermagem, que vem contribuindo efetivamente para o desenvolvimento da pesquisa.

Portanto não me furto, neste momento de grande importância para a profissão, de fazer mesmo que breve, um relato das necessidades em saúde da década de 40 deste século que levaram à criação da Escola de Enfermagem da Universidade de São Paulo. Após isto, passarei a fazer uma reflexão sobre o estado atual da pós-graduação em enfermagem no Brasil pelo fato da pesquisa estar intimamente ligada a esta, como um produto desse processo.

\section{Criaçáo da Escola de Enfermagem da Universidade de Sáo Paulo}

A Escola de Enfermagem na Universidade de São Paulo foi criada através do Decreto Lei Estadual no 13040 de 31 de outubro de 1942. Pode-se estranhar, à primeira vista, porque só na década de 40 esse projeto de criação da Escola de Enfermagem tenha se efetivado, quando já em 1923 havia sido criada a primeira escola de enfermagem no país, no Rio de Janeiro, nos moldes nightingalianos e São Paulo, na segunda década deste século já contava com escolas oficiais de Farmácia, Odontologia, Medicina e Obstetrícia.

As razões da não criação de uma escola de enfermagem em São Paulo, nas duas décadas anteriores, por volta de 1925, relaciona-se ao modelo de prática sanitária que se conformava então, ou seja, o modelo médico-sanitário voltado para ações preventivas individuais, tendo a liderança do sanitarista Geraldo de Paula Souza. Nesse modelo as ações sanitárias visavam a consciência do indivíduo e tinham um caráter educativo e consensual. O caráter educativo e consensual

\footnotetext{
- Enfermeira. Professor Associado da Escola de Enfermagem de Ribeirão Preto da USP.
} 
objetivava contemplar a dinâmica das ciasses sociais e al a presença da classe trabalhadora nas relações de produção do capital industrial que se organizava. $O$ instrumento de trabalho dominante era então a educação em saúde, que visava a consciência do indivíduo a fim de alcançar mudanças comportamentais nos hábitos de higiene a fim de impedir a transmissão de doenças e evitá-las. Todo este aparato de conhecimentos foi buscado nos USA através de sanitaristas brasileiros. E qual o profissional que poderia desenvolver estas atividades educativas, junto aos indivíduos, crianças e famílias? Eram as jovens egressas da Escola Normal que, com um curso de um ano de duração, estavam aptas para realizarem este trabalho educativo, principalmente visando a criança. Assim foi criada em 1925, pelo Professor Geraldo Paula Souza, o Curso de Educadoras Sanitárias, através da Lei Estadual no 2121 de 30 de dezembro.

Portanto, as ações de enfermagem necessárias para atenderem aquele modelo de prática em saúde, que era o médico-sanitário, eram as ações de natureza educativa, a serem desenvolvidas nos centros de saúde, nas escolas e junto às famílias, nas indústrias, através das educadoras sanitárias. Assim, não se fazia necessária a presença da profissional enfermeira.

Nessas primeiras décadas do século XX inicia-se uma colaboração internacional no campo da saúde em toda a América Latina visando o mercado internacional: exportação de matérias-primas, produção agrícola ligada à exportação de alimentos e à indústria extrativa. Assim, tem-se a presença da Organização Panamericana da Saúde, em 1902, voltada para a sanidade marítima e quarentena dos portos e a Fundação Rockfeller, através da Comissão Internacional de Saúde, voltada para o controle das endemias rurais e mais tarde também para a formação de recursos humanos em saúde (1).

Entre as décadas de 20 e 30 inicia-se o incipiente processo de industrialização do país. Com a depressão econômica de 30 provocando o colapso do mercado externo e o decréscimo da capacidade de importação possibilitou que o capital agrícola acumulado no período anterior fosse alocado na indústria para possibilitar a produção manufatureira que até então vinha do exterior. Esse processo de industrialização que se inicia demanda o desenvolvimento de uma atenção médica voltada para a força de trabalho a fim de proteger a mão-de-obra e possibilitar o aumento da produtividade.

Ao modelo sanitário se sobrepõe a assistência médica individual que assume modalidades distintas de acordo com os grupos populacionais a que se destina: classe trabalhadora, onde o Estado intervém através da Previdência Social, e grupos urbanos de classe social alta, atendido através da Prática Médica Privada. O Ministério da Saúde assume a responsabilidade pelas ações coletivas e pela população desprotegida, aquela fora do mercado produtivo.

É nesta conjuntura social que é criada a Universidade de São Paulo em 1934 e em anos anteriores as escolas oficiais da área da saúde e também, na década de 40, o Hospital das Clínicas voltado para o ensino médico. Segundo Amália Corrêa de Carvalho, a "Fundação Rockfeller, por meio de seu Conselho Sanitário Internacional dispôs-se a colaborar financeiramente para a construção e o equipamento da Faculdade de Medicina e do Instituto de Higiene e no iń́cio de 1940, a Fundação enviou a São Paulo a Chefe da Seção de Enfermagem Mrs. Mary E. Tenant, com a incumbência de pressionar as autoridades no sentido da observância dos acordos mantidos anteriormente (...). Apresenta um memorial conten- 
do sugestões sobre os melhores métodos para a organização e o desenvolvimento do ensino de enfermagem. Preconiza o auxilio da Escola ao futuro Hospital das Clínicas sob a forma da Organização do Serviço de Enfermagem, de seleção das enfermeiras que deveriam trabalhar nas enfermarias das clínicas médica, cirúrgica, pediátrica, obstétrica e de doenças contagiosas, as enfermeiras chefes dessas unidades deveriam pertencer ao corpo Docente da Escola assim como a superintendente do Serviço e suas assistentes; aconselha a subordinação da Escola à direção do Conselho Técnico Administrativo da Faculdade de Medicina para que se obtenha organização eficiente e bom funcionamento" (2).

Portanto, nas décadas de 30 e $\mathbf{4 0}$ houve toda uma organização da sociedade brasileira e da paulista em particular para manter e reproduzir o capital industrial e a saúde também se conforma dentro dessa lógica capitalista, protegendo a força de trabalho. O complexo médico-hospitalar se desenvolve para possibilitar o atendimento médico individual, bem como a preocupação com a formação dos recursos humanos em saúde e al destacamos a enfermagem.

Em 1959 a Escola de Enfermagem da Universidade de Sáo Paulo cria cursos de pós-graduação destinados ao preparo de docentes para escolas de enfermagem e de administradores de unidades de enfermagem hospitalar. Os cursos foram de Pedagogia e Didática aplicada à Enfermagem e de Administração de Unidade de Enfermagem, ambos com um ano de duração. "A Fundação Kelogg firmou convênio com a Universidade de São Paulo para a implantação dos mesmos. Esta tinha grande interesse na criação e no desenvolvimento de cursos de pós-graduação em enfermagem num dos países da América Latina a fim de facilitar o cumprimento de um dos seus objetivos, relativo à concessão de bolsas de estudo para enfermeiras dos países da América Central e do Sul. Pelo Parecer no 977/65 do CFE estes cursos foram inscritos na modalidade de especialização. Funcionaram até o ano de 1970 (3).

Observa-se que a Escola de Enfermagem da Universidade de São Paulo sempre esteve atualizada, acompanhando o desenvolvimento do ensino superior no país e, em 1973, após a reforma universitária criou a pós-graduação "sensu stricto", o segundo curso de mestrado em enfermagem no país.

A seguir passaremos a uma reflexão sobre a pós-graduação no Brasil.

\section{A pós-graduaçáo no Brasil}

A pós-graduação no país foi instalada após a reforma universitária implantada a partir de 1968. Foi concebida no país para atender três motivos fundamentais: "1) formar professorado competente que possa atender à expansão quantitativa do ensino superior garantindo, ao mesmo tempo, a elevação dos atuais níveis de qualidade; 2 ) estimular o desenvolvimento da pesquisa cientifica por meio de preparação adequada de pesquisadores; 3 ) assegurar o treinamento eficaz de técnicas e trabalhadores intelectuais do mais alto padrão para fazer face às necessidades do desenvolvimento nacional em todos os setores" (4). "Ela não derivou de um processo espontâneo de crescimento da produção científica e do aperfeiçoamento da formação de seus quadros, mas de uma política deliberada do Estado. Ela obedecia a uma decisão explícita, por parte do governo militar recémestabelecido, de disciplinar e orientar o ensino superior no País. Seu escopo é a 
modernização deste ensino nos quadros do projeto de desenvolvimento económico então adotado (5).

O sistema educacional do país passa hoje por uma grave crise: esta perpassa todos os níveis. Ainda não alcançamos a universalização da educação básica; é alto o grau de analfabetismo, bem como a evasão escolar nos primeiros anos e são poucos os que chegam ao nível superior.

Mesmo nesta profunda crise educacional DURHAN \& GUSSO, ao fazerem uma reflexão sobre a pós-graduação no Brasil, dizem que "esta constitui o setor mais bem sucedido de todo o sistema e isto deve ser considerado como uma conquista a ser preservada." Continuando, expressam que "o éxito é um tanto surpreendente, especialmente quando se considera que resultou de um esforço iniciado há pouco mais de um quarto de século, num sistema universitário marcado por severas deficiências. Logrou-se estabelecer, neste curto lapso de tempo, cursos de mestrado e doutorado de bom nivel em praticamente todas as áreas do conhecimento. E nestes cursos se concentra quase toda a capacidade de pesquisa que se construiu no Brasil e da qual depende a formação de pesquisadores e a qualificação de docentes." (6)

A pós-graduação conta (dados de 1989) com 1.379 cursos, sendo 951 de mestrado e 428 de doutorado, com 46.504 alunos, sendo 36.382 de mestrado e 10.122 de doutorado. Em 1989, titulou 6.037 alunos, sendo 5.040 mestres e 997 doutores. Enquanto o ensino superior se concentra nas instituiçőes privadas com $61,5 \%$ das matríçulas e dois terços dos egressos - a pós-graduação se concentra maciçamente em universidades públicas. De todos os alunos mestrandos do ano de $1989,58,5 \%$ estavam nas escolas federais, $27,5 \%$ nas estaduais e $14 \%$ nas particulares7.

\section{A pós-graduaçáo em enfermagem e a pesquisa no Brasil}

A organização e o desenvolvimento da pesquisa em enfermagem no Brasil são bastante recentes e estão intimamente ligados à pós-graduação "sensu strictus".

Como ocorreu com toda a pós-graduação brasileira, esta não foi instalada após a pesquisa já estar institucionalizada nas universidades. Se assim tivesse ocorrido a pesquisa encaminharia automaticamente para o nivel de pós-graduação e esta já estaria em pleno desenvolvimento. Primeiro a pós-graduação se instalou no bojo da reforma universitária nos últimos anos da década de 60 , em pleno regime autoritário. Assim sendo, falar no poder da pesquisa em enfermagem no Brasil implica falar necessariamente em pós-graduação e ai me proponho a fazer uma descrição sobre como esta se encontra no momento atual e propiciar uma reflexăo conjunta sobre se a estrutura desta atende às nossas necessidades em saúde advindas das grandes desigualdades sociais instaladas no país, ou seja, do nosso modo brasileiro de andar a vida.

A pesquisa como um processo isolado vinculado ao pesquisador e sem uma infra-estrutura para o seu desenvolvimento tem poucas possibilidades de existir e de responder às necessidades dos homens. Ela tem que ser um processo de trabalho coletivo e a pós-graduação vem demonstrando esta possibilidade, se bem que ainda de forma incipiente. E me pergunto como a pós-graduação pode ser uma estrutura que possibilite o desenvolvimento da pesquisa e assim o avanço 
científico e tecnológico da prática de enfermagem. Como explicita Newton Sucupira no seu Parecer sobre definição dos cursos de pós-graduação, "o desenvolvimento do saber e das técnicas aconselha introduzir na universidade uma espécie de diversificação vertical com o escalonamento de níveis de estudos que vão desde o ciclo básico, a graduação até a pós-graduação. Haveria desta forma uma infraestrutura correspondente ao plano de ensino cujo objetivo seria, de um lado, a instrução cientlffica e humanista para servir de base a qualquer ramo e, doutra parte, teria por fim a formação profissional; e uma super-estrutura destinada à pesquisa cuja meta seria o desenvolvimento da ciencia e da cultura em geral, o treinamento de pesquisadores tecnólogos e profissionais de alto nível" (8). E como estes requisitos se conformam e se articulam para possibilitar o conhecimento científico? De forma genérica, a pós-graduaçăo se constitui e se expressa nos seguintes elementos: corpo docente, estrutura curricular, organização da pesquisa, produção cientifica docente, produçáo científica discente, tempo médio de titulação e fluxo de alunos.

Passo agora a fazer uma descrição sumária e genérica da pós-graduação em enfermagem através dos itens apontados acima, tendo por base a última avaliaçáo dos cursos realizada pela CAPES no biênio 90-91 e pelo contato que tive com os cursos nestes últimos anos de 91-92 enquanto Coordenadora da área de Enfermagem junto a CAPES.

CORPO DOCENTE - está constituído na sua maioria por enfermeiros, mas há ainda alguns cursos que para constituir seu corpo permanente contam com a colaboração de outros profissionais da própria instituição de ensino superior e/ou de outras. Quando o curso tem uma natureza multidisciplinar é salutar a presença também de outras categorias profissionais. Quanto ao preparo do corpo docente, observa-se que nem todos os cursos contam com a titulação de doutor de todos os seus docentes. A titulação dos docentes no nível de doutorado vem se mostrando nos últimos anos uma necessidade de primeira ordem, para todas as regiōes do país. Exceção feita ao Estado de São Paulo, que conta com a Universidade de São Paulo que vem formando seus docentes no nivel de doutoramento desde o ano de 1981 quando foi criado o primeiro doutorado no país e que atualmente conta com três e mais um na Escola Paulista de Medicina criado em 1989. Também o Estado do Rio de Janeiro conta com um doutorado na Escola Anna Nery. Os docentes de outras regiōes do país, nestes vinte anos de pós-graduação, em sua grande maioria, so fizeram a titulação no nível de mestre e demandaram muito pouco os cursos de doutorado, que também são em pequeno número no país.

Esta pouca titulação dos professores enfermeiros é também o resultado do estímulo menor das universidades federais para a qualificação bem como das dificuldades de deslocamento para regiōes distantes e das limitações sociais ainda presentes para que a mulher se dedique a atividades intelectuais. Em todos os 10 cursos de mestrado e 4 de doutorado (já avaliados pela CAPES), em 1990 e 1991 havia 221 e 207 professores permanentes respectivamente, sendo 163 doutores em 1990 e 153 em 1991. Porém esta distribuição por curso é muito desigual, há cursos que contam com dois doutores enfermeiros e outros com mais de vinte doutores enfermeiros.

Verifica-se também que para a própria manutenção dos cursos de mestra- 
do e mesmo para o desenvolvimento e atualização da graduação faz-se necessário alcançar o nível de doutorado. É neste sentido que algumas propostas alternativas para suprir a formação de doutores vem se organizando no país como a extensão do Doutorado Interunidades da Universidade de São Paulo para Belo Horizonte na Escola de Enfermagem da Universidade Federal de Minas Gerais e a Rede de Pós-Graduação em Enfermagem para a Região Sul (REPENSUL) que está estendendo o Mestrado da Universidade Federal de Santa Catarina para o Doutorado com a participação de seis Universidades da região sul e criando outros mestrados na região. A região Nordeste conta só com dois mestrados, os da UFBa e da UFPB e vem tentando pensar em organizar um doutorado. As Universidades Federais do Pará e Ceará já estão dando entrada nas propostas de criação de mestrados junto à CAPES.

Outra questão que trouxe dificuldade para o corpo docente da pós-graduação foi a aposentadoria precoce de número considerável de docentes (devido às propostas de mudança na legislação da aposentadoria no país) com titulação e grande experiência em pós-graduação, fato este que desestruturou alguns cursos.

Quanto à idade do corpo docente, observa-se um envelhecimento do mesmo sem a entrada de jovens com titulação para se comporem os quadros. A titulação de grande parte dos enfermeiros, tanto em nivel de mestrado como de doutorado, ainda se dá em idade considerada elevada, em torno dos 40 anos.

ESTRUTURA PROGRAMÁTICA - esta deve manter uma coerência com a natureza do curso, ser suficiente para abranger a área de conhecimento e manter regularidade de oferecimento de disciplinas. Observa-se uma preocupaçăo de quase todos os cursos em atualizar sua estrutura curricular, adequando-a a filosofia do curso. Ela também deve permitir flexibilidade ao aluno dentre um grupo de conteúdos da área de concentração e outro da área conexa. Quanto ao processo de aprendizagem, este deve permitir estimular a iniciativa criadora do aluno.

ATIVIDADES DE PESQUISA - estas devem estar organizadas de forma a atender à natureza do curso e aos problemas de saúde e de enfermagem classificados como prioridade. As atividades de pesquisa expressam-se nas linhas e projetos de pesquisa. A investigação em enfermagem é ainda o resultado de pesquisas e projetos isolados. Não alcançamos a organização da pesquisa em linhas com projetos nas quais haja a convergência de pesquisadores na formação de grupos.

Em alguns cursos as linhas não correspondem à natureza da área de concentração e os projetos têm a participação de pesquisadores isolados.

A organização da pesquisa não se dá de forma mecânica e nem externa aos pesquisadores, ela vai se conformando no próprio processo de produção. Mas também não pode ser deixada à mercê de um processo puramente desordenado; precisa ir sendo analisada e organizada em linhas e grupos de pesquisadores no seu processo de desenvolvimento, sem tirar a característica de criatividade que é tão necessária neste processo.

PRODUÇÃO CIENTÍFICA DOCENTE - as atividades de pesquisa, estão na fase do processo de organização, seja através de linhas e ou de grupos de 
pesquisadores e a produção científica, que ê o resultado destas atividades, ainda deixa muito a desejar. Em alguns cursos ela é quase ausente e em outros ela é considerável. A produção concentra-se nos cursos da USP, UFSC e UFRJ.

Em relação aos cursos, a área de enfermagem na CAPES ainda não analisa a qualidade dessa produção. Isto tem sido objeto de estudo de alguns trabalhos que têm feito análises de teses e artigos publicados em periodicos. Torna-se limitada neste momento, a análise qualitativa da produção docente da pós-graduação quanto uma parte considerável dos cursos conta com pouquíssima produção, portanto ainda a análise quantitativa é a que prevalece. Os cursos de pós-graduação que estão com pouca produção científica docente precisam fazer um estudo buscando as causas desta situação, sejam elas internas aos cursos ou mesmo aquelas resultantes da falta de recursos financeiros e de apoio logístico das entidades financiadoras de pesquisa. Precisam ainda de montar estratégias para que ocorra a produção científica.

Em relação à natureza da produção científica, observa-se que ela se concentra na produção técnica e artística e pouco nas publicações científicas, como artigos em revistas indexadas, e menos ainda em periodicos estrangeiros. Mesmo que a produção de enfermagem tenha muito a ver com os problemas de saúde e da organização sanitária brasileira e portanto de grande interesse nacional, $o$ intercâmbio internacional é necessário, muito salutar e positivo.

PRODUÇÃO CIENTIFICA DISCENTE - como as atividades de pesquisa ainda estão em fase de organização, a produção discente, seja isoladamente, seja junto à docente, ainda é incipiente na pós-graduação. Ela vem sendo estimulada nos últimos cinco anos e quando houver uma organização da pesquisa em linhas, projetos e grupos de pesquisadores, naturalmente a produçáo discente começará a ocorrer, principalmente no nível doutorado que objetiva preparar pesquisadores. duação.

Apresento a seguir alguns dados sobre a produção científica da pós-gra-

\section{PRODUÇÃO CIENTÍFICA E TÉCNICA DOCENTE E DISCENTE, BIÊNIO} 90-91 SUB-ÁREA ENFERMAGEM

\begin{tabular}{l|r|r}
\hline Natureza da Publicação & 1990 & 1991 \\
\hline Artigos Revistas Nacionais & 215 & 198 \\
Artigos Revistas Internacionais & 05 & 10 \\
Livros no Pais & 04 & 11 \\
Capitulos Livros no País & 07 & 30 \\
Capitulos Livros no Exterior & 01 & 02 \\
Trabalhos Completos Congressos Nacionais & 102 & 167 \\
Trabalhos Completos Congressos Internacionais & 01 & 16 \\
Patentes e Protótipos & 03 & 00 \\
\hline
\end{tabular}

FONTE: CAPES/DAA

O quadro acima apresenta o total geral da produção dos cursos, mas o volume da produção se distribui de forma muito desigual em cada curso. Há vários 
cursos, por exemplo, que em relação aos artigos publicados em revistas nacionais em 1991, contribuem com o volume de 1 a 5 publicações e uma proporção menor de cursos contribuindo com 30 a 40 artigos.

TEMPO MÉDIO DE TITULAÇÃO E FLUXO - este ainda é alto, o mestrado está em torno de 4 a 5 anos e o doutorado em 5 anos.

O fluxo é resultado da adequação e interrelação de todos os itens anteriores, ou seja, quando a estrutura curricular é coerente com a área de concentração, com abrangência, regularidade e flexibilidade, quando o corpo docente é altamente qualificado para orientação em pesquisa, está engajado em linha e grupo de pesquisadores e as atividades de pesquisa estão organizadas, permitindo um fluxo mais rápido e com resultados melhores.

CORPO DISCENTE - o número de alunos matriculados no mestrado nos anos 90 e 91 corresponde a 71 e 84 respectivamente e foram titulados também 71 e 72 nestes dois anos. No doutorado foram matriculados 32 e 23, e titulados 28 e 7 nestes mesmos dois anos. Esta distribuição também é desigual em cada curso. Estes dados estão no quadro abaixo.

CORPO DISCENTE - Sub-área Enfermagem, bienio 91/92.

\begin{tabular}{l|r|r|r|r}
\hline \multirow{2}{*}{ Situação dos alunos } & \multicolumn{2}{|c|}{1990} & \multicolumn{2}{c}{1991} \\
\cline { 2 - 5 } & ME & DO & ME & DO \\
\hline Alunos novos matriculados & 71 & 32 & 84 & 23 \\
Alunos em dezembro & 302 & 84 & 225 & 79 \\
Titulados & 71 & 28 & 72 & 07 \\
\hline
\end{tabular}

FONTE: CAPES/DAA

Fazendo uma análise global da pós-graduação em enfermagem instalada no país, que conta com vinte anos, podemos dividir os cursos em três grupos: um grupo de cursos em progresso, outro em estabilidade e um terceiro grupo com queda de qualidade.

Observa-se também uma concentração de cursos nos Estados de São Paulo e Rio de Janeiro, um no sul do país e dois no nordeste e a inexisténcia de cursos na região norte e centro-oeste. O nível de doutorado centra-se também em São Paulo e Rio de Janeiro e as vagas disponíveis ainda não dão vazão à demanda das outras regiões do país.

Nestes últimos dois anos tem havido no país como um todo uma mobilização para a criação de cursos, seja de mestrado como de doutorado, e foram feitas propostas alternativas como a extensão de cursos a universidades que ainda não conta com a pós-graduação, a união de esforços através de consórcios e/ou redes de pós-graduação para sanar a pouca mobilização dos últimos dez anos.

Não estou propondo aqui a abertura de cursos de pós-graduação indiscriminadamente, mas sim somente aonde haja condições infraestruturais, como corpo docente qualificado, cursos de graduação e especialização com bom desempenho, uma produção científica em volume e qualidade suficiente, integração com os serviços de saúde e outras condições necessárias.

Há também a necessidade de fortalecimento de alguns cursos, principalmente aqueles que vem apresentando um retrocesso na sua avaliação. 
Finalizando, volto ao tema desta mesa que é Pesquisa, Poder e Saúde após ter feito uma análise da pós-graduação que tem como um de seus objetivos a produçăo de conhecimento e de pesquisadores. E se a pesquisa só tem razão de ser se estiver voltada para atender às necessidades dos homens, é preciso que este processo seja acompanhado e avaliado de perto medindo-se a sua produção em funçăo das respostas que tem dado à diversidade da situaçăo de saúde do país, que convive com grandes desigualdades sociais: de um lado a concentração de renda em níveis elevados de uma pequena parcela da populaçáo e, de outro, o crescimento da pobreza, do desemprego, o colapso do setor saúde, a alta mortalidade por violência, o extermínio de crianças abandonadas, o recrudescimento das epidemias como dengue, colera e outras.

Se assim for, o processo de pesquisa é um poder que em certa medida pode contribuir para trazer mais felicidade aos homens. Mas volto a insistir novamente, a pós-graduaçăo pode e deve contribuir para o desenvolvimento da pesquisa mas, se podemos contar só com alguns cursos, que no momento atual estão estruturados para esta contribuiçăo, é necessário tambem a contribuição de todos os outros para atenderem às peculiaridades regionais. Para tal, a enfermagem brasileira tem que estar voltada para a problemática da pós-graduação como um todo no pais, procurando fortalecê-la para que o processo de pesquisa se desenvolva e possa contribuir para as transformações da prática de enfermagem.

A Universidade de Săo Paulo, juntamente com outras, vem participando deste processo e penso que tem condições infra-estruturais e de recursos humanos para intervir efetivamente na organizaçăo da pesquisa em enfermagem no Brasil.

\section{REFERENCIAS BIBLIOGRÁFICAS}

1. BRASIL. Ministério da Educaçăo e Cultura. Conselho Federal de Educaçăo. Parecer n9 977/65. Definiçáo dos cursos de pós-graduaçăo. Documenta, n 44, p. 977, dez.

2. CARVALHO, A. Escola de Enfermagem da Universidade de Săo Paulo: resumo histórico 1942-1980. São Paulo, Escola de Enfermagem da USP, 1980. p. 28, 86, 89.

3. DURHAN, E. R.; GUSSO, D. A. Pos-graduação no Brasit. problemas e perspectivas. Brasilia, CAPES, 1991 (mimeografado), p. 2, 4.

4. VERDERESE, $O$. Analise de la enfermeria en la Amtrica Latina. Washington, Organization Panamericana de la Salud, 1980 (Publicacion cientifica, 393). 